\title{
The Dilemma and Adjustment of Livelihood Change in Tibetan Area in Sichuan-A Case Study of Chikalo Village, Aba County
}

\author{
Asha \\ Aba Teachers University, Aba County, China \\ Email: ashade1223@163.com
}

How to cite this paper: Asha (2021). The Dilemma and Adjustment of Livelihood Change in Tibetan Area in Sichuan-A Case Study of Chikalo Village, Aba County. Open Journal of Social Sciences, 9, 427-436. https://doi.org/10.4236/jss.2021.94031

Received: March 13, 2021

Accepted: April 24, 2021

Published: April 27, 202

Copyright $\odot 2021$ by author(s) and Scientific Research Publishing Inc. This work is licensed under the Creative Commons Attribution International License (CC BY 4.0).

http://creativecommons.org/licenses/by/4.0/

\section{(c) (i) Open Access}

\begin{abstract}
What changes have taken place in the livelihood of farmers and herdsmen in Tibetan areas of Sichuan? In the long run, what is the problem with the changed livelihood model? This paper found the answer based on a field survey of villages. The author found that in the research process, the new compound livelihood mode of villages, such as farmland leasing, large-scale animal husbandry and concentrated extraction of medicinal materials, was not sustainable, and the villagers' destructive use of local resources without any technical processing accelerated the consumption of grassland and farmland resources, breaking the ecological balance maintained by the local traditional livelihood. When income from animal husbandry and medicinal materials collection is dominant, problems such as unstable market, sharp decrease of medicinal materials resources, reduced yield and quality of grassland will only lead to uncertainty and high risk of new compound livelihood model of villages, and even lead to poverty.
\end{abstract}

\section{Keywords}

Livelihood Change, Marketization, Economic Rationality, Ecology

\section{The Question Raised}

Chikalo Village in Tibetan area of Sichuan is an administrative village located in the southeast direction of Aba County, Aba Prefecture, about 6 kilometers away from the county seat. According to the latest data of the 2020 national census, the total number of households in the village is 191, and the total number of people in the village is 973 , not counting the newly born people. The villagers have been using the livelihood model of combining farming and animal hus- 
bandry for generations. However, in the process of market-oriented development, the original livelihood model has changed. The villagers have successively chosen to rent the farmland, excavate medicinal materials in the mountains and expand the scale of breeding, so as to realize the maximum income. The empirical research materials of this paper come from the author's field research in Chikalo Village of Aba County in 2015, 2017, 2019 and 2020. The methods of data collection include literature, in-depth interview and observation. In the process of marketization, what changes have taken place in the livelihood mode of Tibetan people in Tibetan areas of Sichuan? What kind of difficulties are you encountering? From the perspective of environmental sociology, this study aims to deepen our understanding of the reasons for the change of livelihood mode in Tibetan areas, and further deepen our understanding of the relationship between livelihood, market and ecology in ethnic areas. One of the key points of rural revitalization in ethnic areas is to guide them out of the dilemma of modernity, endow development with new connotation and play its due role.

\section{Traditional Farming and Animal Husbandry Livelihood}

Until the middle and late $20^{\text {th }}$ century, because of the low commodity rate of agricultural and animal husbandry products, the livelihood mode of combining farming and animal husbandry in Chikalo village was in a virtuous circle of self-sufficiency, and the villagers had insufficient motivation to expand the production scale. In their daily livelihood, villagers should try their best to play the role of both planting and breeding industry to obtain livelihood security. In the traditional dietary structure of Tibetan people, highland barley flour plays a pivotal role as the staple food. "At that time, highland barley was very important," said villager Ram. "Sometimes it could be used as a substitute for currency and barter for barter." The planting structure of Chikalo village has always been based on highland barley, supplemented by peas, potatoes, etc. However, due to the limitations of objective natural conditions, infrastructure, and the recultivation index (one crop per year), the per-mu grain yield is much lower than that of the mainland. Each household is allocated enough farmland, in order to restore the soil and reduce soil loss, the village to implement the rotation tillage system. The highland barley planting is basically through the mutual assistance and guarantee mechanism in the village. Neighbors and relatives change jobs to complete the work without hiring help.

In addition, the commercialization of livestock products has been very low. Cattle and sheep farming is deeply embedded in the daily life of Tibetans and is used for food, clothing, housing and transportation. Wear cow skin boots, take black tents woven with cow hair, storage bags woven with cow hair, use dry cow dung as fuel, eat beef, drink milk tea... During the period of the people's commune in the middle and late $20^{\text {th }}$ century, the livestock grazing in the village was very limited, with less than 500 cattle, and the rate of stocking was very low. In the late 1990s, villagers pulled donkey carts or tractors into the city to sell dried 
cow dung for 1.5 yuan a sack. Although chicken, pork and fish are also available, most Tibetans on the plateau are accustomed to eating highland beef and mutton. At that time, the commercialization degree of cattle, sheep and highland barley crops was low. After meeting the needs of their families, the price of the remaining products in the market was not high. Villagers' annual production time nodes are as follows: in May, they sow barley potatoes and peas; From June to August, grazing in the nearby summer pasture; In September, he went down to harvest highland barley. In October the cattle and sheep go down the mountain and breed in the winter meadows. The traditional livelihood model adapts to the local natural environment, and the villagers temporarily form a balance in the process of obtaining the local ecological resources. In some ways, this is similar to Marx's description of the French countryside in the $19^{\text {th }}$ century: "Every peasant household is nearly self-sufficient, producing most of his own consumer goods directly, and thus obtaining the means of subsistence more by exchange with nature than by interaction with society."

\section{Impact of Modernity: Livelihood Change and Marketization}

After entering the $21^{\text {st }}$ century, villagers have become more sensitive to the market, more convenient transportation in the village, and more and more channels for villagers to obtain information and production factors. As the market economy surged forward, the production and management of the villagers were unsurprisingly forced to be involved in the global commodity circulation system. With the price of agricultural products lifted, farmers also began to step on the process of marketization, which greatly aroused their enthusiasm for production and management. For example, with the continuous improvement of marketization, highland barley, cattle and sheep, and medicinal materials have all been brought into the market for trading, and the production activities of the villagers in Chikalo Village are increasingly closely related to the market. With the increasing market demand, the prices of cattle and sheep, cordyceps fungus and fritillaries are constantly rising, and the motivation of the villagers to pursue profit maximization is also increasingly strong. The impact of modernity on the villagers is that the economic logic defeats the traditional ecological culture's reverence and worship for nature and turns to the unrestrained demand for natural resources.

\subsection{Invest in Foreign Capital and Technology to Grow on a Large Scale}

Highland barley cultivation has low income and high cost, and its importance in the diet structure has been greatly weakened, and the villagers lack of planting power. In terms of dietary habits, due to the easy access to rice and flour flowing into the market, the traditional dietary habits of the Tibetan people have changed, and the highland barley flour has become replaceable on the table. Rice and stir-fried vegetables, for example, are eaten more frequently in households 
with a moderate or higher income level in the village of Chikalo. Even, the diet structure has become a standard to measure their family economic conditions. In the 1980s, the household contract responsibility system was put into effect in Chikalo village. The total area of arable land was 185.2 hectares, and a total of 575 villagers were allocated land. Highland barley seed improvement, yield increase. Traditional local highland barley seed yield $1500 \mathrm{~kg}$ per hectare, in 1996, the village planted an improved variety "Kangqing No. 3", the per hectare yield can reach $3750 \mathrm{~kg}$. However, the planting time and economic cost of highland barley are still high and the profit difference is not high. From late April to early October every year, the following links of highland barley planting should be carried out successively: arable land, fertilization, sowing, weeding, harvesting and threshing, etc. In recent years, the cost of agricultural supplies has been rising year after year, and the cost of renting pesticides, fertilizers, arable land machinery, harvesting workers or harvesters has continued to rise. According to the data in Table 1 and Table 2 of the author's survey in this area in 2014, excluding the cost, the average income per mu of land is only 330 yuan, regardless of the farmland fertility. Although the annual sale price of highland barley is not large, but the input cost is "rising", the net income of production is limited. Highland barley income is almost equivalent to investment, but no profit of chicken ribs. Chikalo village committee member Jeb said: "Now it is almost impossible to make money planting highland barley, the old people do not plant, young people do not want to plant. Before there is no basic because of sloping land is not good on the wasteland. There's a lot of good stuff going to waste right now."

Highland farming has also entered the capital- and technology-driven market operation process, and outside contractors began to lease farmland. As farming becomes more risky, villagers are increasingly turning their sloping land into wasteland or renting it out to skilled and well-funded outside contractors, damaging the fragile ecological environment. The contractor specialises in planting cash crops such as cucumber, lotus, lettuce, white gourd and pea, and frequently applies chemical fertilizers and pesticides, damaging the quality of the leased

Table 1. Land production cost of each production unit in 2014.

\begin{tabular}{ccccccc}
\hline farmers & Farming area & seeds & fertilizer & mechanical & employees & Total spending \\
\hline JiGuo & 2 hectare & 2760 yuan & 800 yuan & 1000 yuan & 3800 yuan & 8360 yuan \\
ram & 1 hectare & 900 yuan & 200 yuan & 300 yuan & 400 yuan & 1400 yuan \\
\multirow{2}{*}{ Eva wang } & 1 hectare & 960 yuan & 200 yuan & 350 yuan & 400 yuan & 1910 yuan \\
\hline
\end{tabular}

Table 2. Land output of each production unit in 2014.

\begin{tabular}{ccccccc}
\hline farmers & varieties & production & The unit price & Total revenue & Total spending & Net income \\
\hline JiGuo & Kangqing No. 3 & 6900 catties & 2 yuan $/ \mathrm{kg}$ & 13800 yuan & 8360 yuan & 5440 yuan \\
ram & Kangqing No. 3 & 2250 catties & 2 yuan $/ \mathrm{kg}$ & 4500 yuan & 1400 yuan & 3100 yuan \\
Eva wang & Kangqing No. 3 & 2400 catties & 2 yuan $/ \mathrm{kg}$ & 4800 yuan & 1910 yuan & 2890 yuan \\
\hline
\end{tabular}


farmland. The old village rules and customs declined, and the rotation tillage system of one rest a year was cancelled. The annual cultivation and use of farmland would inevitably lead to the loss of soil fertility. Shards of white plastic film scattered in the vegetable fields of greenhouses have polluted the plateau farmland. For economic reason, the villagers welcome contractors. Villager Ren Qing said in an interview in July 2019, "With so many pesticides being used in the fields, the fertility of the land must be getting worse every year as they grow vegetables." In summer, the young and middle-aged people go to the mountains to dig medicinal herbs. The old people who stay at home can also go to the vegetable fields to work, weed, collect vegetables, etc., and do temporary jobs to earn some money. Most villagers pay more attention to the small economic gains in the short term, and seldom consider whether the large ecological environment will be damaged in the long term.

In the process of livelihood change, only the cultivation form of planting industry has been retained, but its livelihood has undergone qualitative change. On the one hand, the villagers only collect rent, they do not have market capital and planting technology, they are unable to carry out large-scale planting independently, they have no subjective initiative, and they have little profit. On the other hand, intensive large-scale farming has increased many uncertainties, and the high-consumption land has made destructive use of the fragile local ecological environment, which is not conducive to the sustainable development of the Qinghai-Tibet Plateau region.

\subsection{The Price of Medicinal Materials Rose, and the Villagers Collected Them Intensively}

Marketization drove the commercialization of medicinal materials. Tibetans began to collect medicinal materials more intensively and professionally from the perspective of economic rationality and logic, ignoring the taboos of mining. With the intensification of mobility, in the communication with urban culture, villagers accept the economic rationality implied by urban culture, and take it as their own standards of measurement and code of conduct (Yang Meiqin \& Tang Ming, 2019). After 2000, prices soared. In the market of cordyceps, the price of cordyceps in Tibet is the highest, followed by Qinghai Yushu, and the third is Qinghai Guoluo state. Aba County is located in the junction of Sichuan Province, Gansu Province and Qinghai Province, sensitive to the market dynamics, and the medicine economy has rapidly constructed a new livelihood model for the local. In addition to mining medicinal materials in Aba County, $70 \%$ of the villagers would choose to go to the counties in Guoluo Prefecture, Qinghai Province, which is not far away, to harvest as much economic profit as possible. Obviously, such behavior logic is contrary to the intention of protecting the ecological environment of the Qinghai-Tibet Plateau. Under the rules of traditional Tibetan ecological culture, Tibetans hold the concept of sacred mountain worship and animism, and avoid digging the grassland of sacred mountain (Zhou Ta, 2010). However, the high income from the sale of medicinal materials, 
people began to ignore all this. Every year from May to September in the medicinal materials mature season, the villagers have to launch a fierce competition to dig. Several families familiar with each other in the village formed teams to contact and rent grassland in Jiuzhi County, which is more than 70 kilometers from Aba County, or Dari County, which is farther away. On the grasslands 4000 meters above sea level or even higher, villagers set up tents, go out early and come back late, crawl and dig medicinal materials, unimpeded by snow and snow to earn a living. From the middle of May to the middle of June, the caterpillar fungus is picked. Late June to the end of August, is the Fritillaria time. The mining time will last 4 - 5 months. During the summer vacation in July-August, villagers also pick up children over the age of 10 to dig. In September, the whole family dug up the Cordyceps Fritillaria, with a total income of more than 50,000 to 80,000 yuan. This has formed a special nature, there is a great uncertainty of the cordyceps economy (Liang Yaxi, 2012).

During the period from 2015 to 2020, the market of medicinal materials fluctuated, the rent of grassland increased, the amount of excavation decreased and the income dropped sharply. According to the author's investigation, the market of medicinal materials is deeply affected by the global economy, and the price fluctuation is very frequent and unstable. Due to the sharp decline in the resources of medicinal materials on the plateau, the amount of medicinal materials collected by villagers has been decreasing year by year in recent years. One kilogram of cordyceps is equivalent to 2000 pieces of cordyceps. On bad days, one piece of cordyceps can not be collected all day. The average family has two mining labor force, it is very difficult to collect the amount of 1 jin. In the interview, the villager said: "In the past, if you worked hard for four months, you could relax for a whole year. Now there are fewer and fewer cordyceps. Sometimes, not a single cordyceps can be found in a day." In addition, after digging the ground, the villagers also collect and sell the top seeds of the fritillaria, which greatly affects the growth of the next year, resulting in a continuous decline in the yield of the fritillaria in recent years. As can be seen from Table 3, prices of cordyceps fluctuated greatly in 2015, 2017 and 2019. Aba Prefecture and Guoluo Prefecture successively implemented the grassland ecological protection policy, and the restriction of medicinal materials mining increased. As can be seen from Table 4, in 2015, 2017 and 2019, pasture rents are rising and the cost of medicinal material extraction continued to rise. Before leaving, villagers need to prepare all the supplies they need to live during the digging period, the high rent of pasture,

Table 3. Cordyceps varieties prices in Guoluo prefecture, Qinghai province.

\begin{tabular}{cc}
\hline year & The price \\
\hline In 2015 & 40,000 yuan $/ \mathrm{kg}$ \\
In 2017 & 50,000 yuan $/ \mathrm{kg}$ \\
In 2019 & 30,000 yuan $/ \mathrm{kg}$ \\
In 2020 & 40,000 yuan $/ \mathrm{kg}$
\end{tabular}


Table 4. Rental of grazing land for medicinal herbs.

\begin{tabular}{cccc}
\hline year & In 2015 & In 2017 & In 2019 \\
\hline Fritillaria pasture rent & 1000 yuan & 2000 yuan & 2000 yuan \\
Cordyceps pasture rent & 5000 yuan & 6000 yuan & 7000 yuan \\
\hline
\end{tabular}

and medical expenses to cope with cold and cold. In order to cope with these expenses, many villagers choose to borrow, private lending needs to pay a lot of interest. Now the collection of medicinal materials has decreased, the price of medicinal materials has fluctuated, the profit of medicinal materials has decreased sharply, and the cost of extraction has increased rather than decreased. As a result, villagers are trapped in poverty, a cycle that is fueled by a volatile market. Therefore, the economy of medicinal materials has high risk, uncertainty and unsustainability.

Over harvesting of cordyceps fungus and fritillary fungus year after year has also caused serious damage to the fragile ecological environment of the Qinghai-Tibet Plateau. For example, the cordyceps extracted by the villagers in Chikalo Village grows on the Qinghai-Tibet Plateau, where the ecological environment is very fragile. After the excavator's scavenging by crawling, the grass is not backfilled after the cordyceps extracted, and the grass is full of pits. In addition, with the visit of the mining crowd, there are vehicles and motorcycles run over and household garbage scattered, etc. This destructive and resource-consuming way of living will inevitably affect the growth of herbage and medicine in the coming year and break the local ecological balance.

\subsection{Extensive Management, Expand the Scale of Breeding}

Since 2000, Chikalo village animal husbandry accelerated development period. Different families adopted different livelihood strategies, and many villagers with economic strength began to concentrate on expanding the scale of livestock breeding to improve economic benefits. In 1998, Aba County implemented the grassland reform. Based on historical evolution and population base and other factors, the grassland was allocated to each administrative village. The total grassland area of Chikalo Village was 58,772.28 mu. In the 1990s, the number of cattle and sheep in each household in the village is still small, but it has a small scale. In the village of Chikalo, for example, the Wazai family's cattle have increased from three to 15 . Around 2000, the commodity rate of pollution-free livestock products on the plateau increased, the market raised the price of cattle and sheep, and the economic benefits of animal husbandry increased. In order to increase their income, the number of livestock in the village began to increase rapidly. Many families with moderate income, who had previously raised 50 100 yaks, bought more and raised 200 - 400 yaks. However, the operation mode of "relying on nature to raise livestock" is relatively extensive. The villagers only rely on machinery to increase the number of livestock inventory to increase income, without relying on science and technology, and there is almost no other 
processing of livestock products. This way of doing business, in a brutal global market system, clearly has no competitive advantage. In addition, because of the special climatic conditions on the Qinghai-Tibet Plateau, natural disasters such as hailstorms and snowstorms occur frequently, and livestock are stolen, or cattle and sheep are infected with diseases. Therefore, the livelihood of livestock breeding is unstable and at high risk.

The scale of villager breeding far exceeds the bearing capacity of grassland, resulting in grassland degradation. After the cattle and sheep market became hot around 2000, the villagers followed the trend and expanded the scale of breeding. However, the increase in the number of cattle and sheep, coupled with the extensive herdsmen's feeding methods, the natural grassland is not enough to sustain the normal feeding of livestock, and the grazing pressure on the grassland ecosystem continues to rise until the grassland is overloaded. Cattle and sheep are in the bad cycle of "full in summer, fat in autumn, thin in winter and dead in spring". Livestock are seriously lack of nutrition, and the yield of young has decreased significantly, which makes it difficult to maintain animal husbandry. In the cold season, the amount of forage in the grassland is less, and the overloading rate is higher. The dense herds have to eat grass roots when the forage is in short supply. In the season of grassland greening, the growth and development of plants are seriously damaged. Under the distress of the shortage of grassland resources, in order to maintain a livelihood or even increase income, villagers need to buy more supplemental forage grass and highland barley straw in winter, and they also need to rent pastures with higher yield and better quality of forage grass from other villages in winter, resulting in a sharp rise in livestock costs. Compared with 2000, in 2015 and 2020, both the carrying capacity and the stock capacity of livestock in Chikalo village of Aba County showed an increasing trend, and the breeding cost increased. Studies by some scholars show that under the impact of institutional change and market competition, the poverty rate of herdsmen has risen sharply (Wang, 2009). The ecological and environmental cost of extensive traditional overgrazing is incalculable, and grassland degradation is becoming more and more serious. Needless to say, the villagers of Chikalo are so passively entwined in the global market chain that they compete with each other by selling raw, unprocessed livestock products. However, in the face of the choppy end market, without technology and capital, the villagers will undoubtedly suffer the most direct and powerful impact passively. In addition, the expansion of extensive farming without active human protection will suddenly increase the consumption of grassland resources, resulting in a sharp decrease in the amount of forage grass, aggravating grassland degradation, and the sustainable development of extensive farming livelihoods.

\section{Conclusion and Suggestions}

\subsection{Conclusion}

The livelihood mode after the transition is easily affected by the market fluctua- 
tions, and at the cost of higher resource consumption, the local farmers and herdsmen enter into a mode of high cost input and high risk coexistence. On the one hand, in order to maintain their current livelihood, the villagers depend on the medicine economy or livestock breeding, which is deeply affected by market fluctuations, and their livelihood is particularly fragile. On the other hand, modernity has brought more and more costs for weddings and funerals, housing construction costs, children's education input, medical expenses, etc., and the living expenses cannot be reduced, resulting in increasing pressure on villagers. This has broken the original economic balance of the villagers' families and even led them into poverty.

Due to the unwary and destructive use of resources and the volatility of global markets, new ways of living after the change face increased uncertainty. Most villagers compete in the market only by selling raw materials, lack capital and skills, and are limited by market and ecological resources. At present, the villagers are in urgent need of an alternative livelihood model with more development potential and sustainability. The families whose incomes are dominated by medicinal materials have seen their incomes decrease year after year, and they do not have enough funds to buy cattle and sheep. Households, where income from livestock is dominant, are also constrained by limited pasture resources, rising farming costs and fluctuating markets. The villagers began to worry about their lives.

Undoubtedly, the new livelihood mode of the villagers has entered an awkward situation. Leasing farmlands, increasing the use of pesticides and fertilizers, and ending rotation tillage, resulting in farmland loss; Livelihood changes such as the expansion of livestock farming and the intensive mining of medicinal herbs have temporarily sustained the villagers' daily lives. However, these modes of production and operation are in the final analysis of no technical content, the productions of products are also located in the market chain of the most primitive link. At the same time, the three paths have caused harm and consumption to the environment in different degrees, and even gradually lead to the direction of excessive resource extraction. Here's a dilemma: Do villagers continue to overextract resources in order to survive? Or should we take ecological resources into consideration and try our best to achieve mutually beneficial economic and environmental outcomes? The author believes that there is no antagonistic relationship between the two. Technology and capital do not necessarily destroy the ecological balance. The key is that development needs to be carried out within the framework of ecological protection. The premise of ecological protection is to ensure the livelihood of villagers. Villagers should not sacrifice their livelihood and become outsiders of economic development in order to protect the ecological environment. Utilization and protection can go hand in hand.

\subsection{Suggestions}

First, government should continue to strengthen and complete the education of 
young people. The local government needs to face and solve the current difficulties and problems in education in Tibetan areas with the greatest sincerity, especially in rural areas and the education of ordinary farmers and herdsmen, and attract school-age children to complete the nine-year compulsory education by means of government subsidies and proper dissemination and guidance. We will continue to develop and encourage the training mechanism for senior talents in Tibetan areas and optimize the professional knowledge structure of college and technical secondary school students. Basic education and vocational skills training must be regarded as the top priority in the long-term solution to the problems in Tibetan areas.

Second, vigorously develop ecological agricultural products with Plateau characteristics. With the continuous growth of China's economy in the past 30 years, the income level of urban and rural residents continues to increase, and the consumption structure has also undergone major changes. The food demand has shifted from the low level of "satiety" to the high level of "well eaten", and there is an increasing demand for green, organic and other featured high-end food. The unique climate and ecological conditions in Tibet are precisely conducive to the production of such high-end agricultural products. This will undoubtedly attract more rural labor and provide a new way for farmers to increase their income.

\section{Funding}

School level planning project of $\mathrm{ABa}$ Teachers University: Livelihood vicissitude of farmers and herdsmen in Tibetan area of Sichuan Project No: ASB20-07.

\section{Conflicts of Interest}

The author declares no conflicts of interest regarding the publication of this paper.

\section{References}

Liang, Y. I. (2012). Cordyceps Sinensis and Tibetan Medicine in the Globalization of Tibet. Cultural Review, 2, 56-63.

Wang, X. Y. (2009). Livelihood of Herdsmen under Drought: A Survey of Baiyin Hagatun in Xing'an League. Journal of Central China Normal University (Humanities and Social Sciences Edition), 4, 18-26.

Yang, M. Q., \& Tang, M. (2019). Research on the Modern Dilemma and Transformation Path of Traditional Ecological Culture in Ethnic Areas. Guizhou Social Sciences, 3, $94-$ 101.

Zhou, T. (2010). Worship Mountain and Sacrifice God-On the Objective Effect of Tibetan Sacred Mountain Concept on Ecological Protection. Gansu Social Sciences, 3, 159 164. 